\title{
Retroperitoneal lymphangioma: A report of 2 cases and a review of the literature regarding the differential diagnoses of retroperitoneal cystic masses
}

\author{
MARIACRISTINA DI MARCO, ELISA GRASSI, SILVIA VECCHIARELLI, \\ SANDRA DURANTE, MARINA MACCHINI and GUIDO BIASCO
}

\author{
Department of Experimental, Diagnostic and Speciality Medicine, University of Bologna, \\ Sant'Orsola-Malpighi Hospital, I-40138 Bologna, Italy
}

Received March 9, 2015; Accepted December 17, 2015

DOI: $10.3892 / 01.2016 .4367$

\begin{abstract}
Cystic lymphangioma is a type of benign tumor originating from the lymph vessels. The tumor commonly occurs in childhood, in the head or neck regions, and retroperitoneal localization and presentations in adulthood are rare. Determining a pre-operative diagnosis is often challenging, and in the majority of cases, a diagnosis is only possible subsequent to the histological examination of the surgical specimen. A radical resection is the recommended treatment for cystic lymphangioma, and recurrence is usually due to an incomplete excision of the mass. The present study reports 2 cases of cystic lymphangioma, localized in the pancreatic gland and duodenal wall respectively, which were treated with surgical resection. The study also briefly reviews the literature regarding the differential diagnosis of retroperitoneal cystic masses.
\end{abstract}

\section{Introduction}

Lymphangioma is a rare benign neoplasm, described for the first time by Koch in 1913 (1). The tumor is rare, and its exact incidence is unknown (1). It originates from a congenital malformation of the lymphatic channels, due to an obstruction of the lymphatic ducts, and results in lymphangiectasia. The disease most frequently occurs in the pediatric age group, and $\sim 90 \%$ of cases are diagnosed prior to 2 years of age. The most common sites of the tumor are regions of the neck, head and axillae, while abdominal localization is rare (1).

The majority of abdominal lymphangiomas, which account for $1 \%$ of all lymphangioma cases, are localized in

Correspondence to: Miss. Elisa Grassi, Department of Experimental, Diagnostic and Sepciality Medicine, University of Bologna, Sant'Orsola-Malpighi Hospital, 9 Massarenti Street, I-40138 Bologna, Italy

E-mail: elisa.grax@gmail.com

Key words: cystic lymphangioma, cystic mass, retroperitoneum, pancreas, differential diagnosis retroperitoneal or mesenteric sites, and pancreatic localization is rare. They are usually symptomatic and found accidentally (2). In symptomatic cases, the clinical presentation includes abdominal pain and distension. Symptoms may rarely be associated with complications, including intracystic bleeding, infection, cyst rupture or compression of adjacent organs (3). Diagnostic techniques include computed tomography (CT), magnetic resonance imaging (MRI) and endoscopic ultrasound with cyst fluid fine-needle aspiration, however, a definitive diagnosis of cystic lymphangioma is typically achieved by histological examination subsequent to surgery or exploratory laparotomy (3). Radical surgery is the recommended treatment for abdominal lymphangiomas, therefore, recurrence is rare and usually occurs due to an incomplete resection. Conservative methods, including aspiration, cyst enterostomy and peritoneal marsupialization, are now obsolete due to the high rate of recurrence (2).

The present study reports 2 cases of retroperitoneal cystic lymphangioma that were treated by radical surgical resection and briefly reviews the literature regarding the differential diagnoses of retroperitoneal cystic masses.

\section{Case report}

Case 1. In July 2012, an asymptomatic 43-year-old man, with no history of pancreatic or other gastrointestinal anomalies, received an abdominal computed tomography (multidetector CT using a 16-detector row system; Siemens AG, Munich, Germany) scan at Sant'Orsola Malpighi Hospital (Bologna, Italy) due to the accidental finding of hypertransaminasemia during a routine checkup. CT images were acquired using a triphasic scanning technique, with scan delays of 35, 80 and $180 \mathrm{sec}$ for the early arterial, portal venous and late portal venous phases, respectively, following intravenous injection of $150 \mathrm{ml}$ of iodinated contrast solution (Xenetrix ${ }^{\circledR}$; Guerbet, Roissy CdG Cedex, France), at a rate of 2-3 ml per sec. Multiplanar reconstructions were used to identify vascular anatomy. Response Evaluation Criteria In Solid Tumors were used to evaluate anatomic disease staging. Analysis was performed using tumor size (in $\mathrm{cm}$ ) and attenuation coefficient (in Hounsfield Units) of the mass on the CT images. The CT 
scan revealed the presence of a $82 \times 73 \mathrm{~mm}$ voluminous multichamber cystic formation with a fluid content in the left side of the abdomen, which extended from the large curvature of the stomach to the pancreatic tail, with no infiltration of the adjacent parenchyma. The cystic fluid was aspirated for cytological characterization using CT-guided needle aspiration, and the presence of serous material with small, mature and atypical lymphocytes and the absence of epithelial and neoplastic cells was determined. Due to the risk of malignancy, surgery was planned. A distal splenopancreasectomy was performed to remove the adherent cystic lesion. Specimens were prepared for routine histopathological examination using hematoxylin and eosin staining. Briefly, sections were fixed in $4 \%$ paraformaldehyde (Sigma-Aldrich) and paraffin-embedded (Merck Millipore, Darmstadt, Germany). Sections (7- $\mu \mathrm{m})$ were then cut and stained with hematoxylin and eosin (Sigma-Aldrich, St. Louis, MO, USA) and observed under a light microscope (Eclipse E800; Nikon Corporation, Tokyo, Japan). The histological examination of the lesion revealed multichamber cysts that were formed from epithelial elements. For immunohistochemical analysis, the sections were deparaffinized $(100 \%$ xylene for $2 \mathrm{~min}$, three times), rehydrated (100\% ethanol for 2 min, three times; $95 \%$ ethanol for 2 min, three times; $80 \%$ ethanol for $2 \mathrm{~min}$, three times; $50 \%$ ethanol for $2 \mathrm{~min}$, three times; distilled water for $2 \mathrm{~min}$, two times) and boiled in citric acid (Sigma-Aldrich) for $20 \mathrm{~min}$. All slides were cooled with running tap water and equilibrated for $20 \mathrm{~min}$ at room temperature (RT). Endogenous peroxidase activity was blocked using $3 \%$ hydrogen peroxide for $15 \mathrm{~min}$ at RT, followed by 2 washes with water and phosphate-buffered saline (PBS) at room temperature for $3 \mathrm{~min}$. The sections were then incubated with bovine serum albumin and skimmed milk in PBS (blocking solution) for $1 \mathrm{~h}$. Next, the sections were incubated with monoclonal mouse anti-human CD31 (catalog no., 89C2; Cell Signaling Technology, Inc., Danvers, MA, USA) or monoclonal mouse anti-human HMB-45 (catalog no., MA5-16712; Thermo Fisher Scientific, Inc., Waltham, MA, USA) primary antibodies at a dilution of $1: 100$ for $16 \mathrm{~h}$ at $4^{\circ} \mathrm{C}$. Sections were washed twice in PBS at room temperature for $3 \mathrm{~min}$ and the antibody signals were detected by secondary antibodies included in the Histofine Immunohistochemical staining kit (catalog no. 414151F; Nichirei Biosciences Inc., Tokyo, Japan) according to the manufacturer's instructions. The sections were counterstained with hematoxylin and observed under a light microscope (Eclipse E800; Nikon Corporation). Immunohistochemically, the endothelial cells lining the surface of the cystic space expressed cluster of differentiation (CD)31, but not monoclonal mouse anti-human melanosome, clone HMB-45 (HMB-45), which is compatible with a diagnosis of cystic lymphangioma originating from the pancreatic lymph vessels. The post-operative course was uneventful. The patient was enrolled in a clinical and instrumental follow-up program. Clinical follow-up and radiological investigations with alternating abdominal ultrasound and $\mathrm{CT}$ scans were performed every 6-8 months for the first 2 years following surgery, and annually for the subsequent 3 years. The patient remains alive and free from disease at 3 years and 4 months after surgery.

Case 2. In October 2012, a 29-year-old man was hospitalized at Sant'Orsola Malpighi Hospital (Bologna, Italy) due to the progression of anemia. During the patient's hospitalization, a gastroscopy was performed to assess the cause of the anemia, which revealed a circumferential lesion in the third region of the duodenum. The biopsy that was performed during the endoscopy examination revealed the presence of intestinal lymphangiectasia. A CT scan (multidetector CT using a 16-detector row system; Siemens AG) demonstrated the presence of thickened jejunal loops with signs of stenosis and hypovascularization. Positron-emission tomography with $18 \mathrm{~F}$-fluorodeoxyglucose $\left({ }^{18} \mathrm{~F}-\mathrm{FDG}\right.$ PET) revealed the presence of abdominal tissue with medium glucose metabolism in the duodenal-jejunal region. The patient underwent surgery, and during the laparotomy, the voluminous cystic mass located in the third region of the duodenum was identified, which demonstrated intraluminal and exophytic development in the mesenteric region. The patient underwent an en bloc resection of the third region of the duodenum, extending to the jejunum and the fourth region of the duodenum. To re-establish gastrointestinal continuity, a side-to-side jejunoduodenostomy was performed. Tissues were prepared for histological examination as described previously for case 1 . The histopathological examination confirmed the pre-operative diagnosis of cystic lymphangioma, and revealed that the proliferation of lymphatic and blood venous vessels extended to the duodenal wall and perivisceral adipose tissue. The lymphatic component was filled with eosinophilic serous material. The post-operative course was uneventful. The patient was followed up with clinical and radiological controls. Clinical follow-up and radiological investigations with alternating abdominal ultrasound and $\mathrm{CT}$ scans were performed every 6-8 months for the first 2 years following surgery, and annually for the subsequent 3 years. The patient remains alive and free from disease at 3 years and 3 months after surgery.

\section{Discussion}

Despite the rare incidence of the disease, cystic lymphangioma possesses differential diagnostic criteria compared with other retroperitoneal cystic masses. The benign tumor originates from the abnormal development of the lymphatic structures that are commonly localized in the head and neck regions ( $75 \%$ of cases) or the axilla region (20\% of cases), and usually occurs in the pediatric age group. An abdominal localization and presentation in adulthood is extremely rare. In general, abdominal lymphangioma occurs in the mesenteric region; occurrence in the mesocolic and retroperitoneal regions, and the walls of the small and large intestines are rarer (4).

Pancreatic cystic lymphangioma is a type of retroperitoneal lymphangioma, which only represents $0.2 \%$ of all pancreatic tumors and possesses differential diagnostic criteria compared with other cystic pancreatic and extra-pancreatic neoplasms, or compared with non-neoplastic lesions. Unlike the lymphangiomas of retroperitoneal origin, which occur more frequently in men, pancreatic lymphangiomas are more common in women (male:female ratio, 16:29), and are localized preferentially in the pancreatic body, not in the head $(5,6)$. The etiology of this finding remains unclear. According to the most popular theory, these lymphangiomas develops from a congenital malformation of the lymphatic channels that dilates, resulting in the formation of 
Table I. Type and characteristics of neoplastic retroperitoneal cystic neoplasms.

\begin{tabular}{lcccc}
\hline $\begin{array}{l}\text { Type of } \\
\text { cystic neoplasm }\end{array}$ & $\begin{array}{c}\text { Epidemiological } \\
\text { and clinical features }\end{array}$ & $\begin{array}{c}\text { Morphologic features on } \\
\text { ultrasound and CT scan }\end{array}$ & $\begin{array}{c}\text { Malignant } \\
\text { potential }\end{array}$ & First author \\
\hline
\end{tabular}

Cystic teratoma

Female gender, new-borns, usually asymptomatic

Cystic

mesothelioma

Müllerian cyst

Epidermoid cyst

Tailgut cyst

Bronchogenic cyst

Cystic changes in solid neoplasms

Pseudomyxoma retroperitonei

Cystic

lymphangioma

Cystic neoplasms of the pancreas
Female gender, abdominal pain, not associated with prior asbestos exposure Female gender, childbearing age, obese women with menstrual irregularities receiving hormonal therapy Female gender, middle age, asymptomatic or symptoms due to a local mass effect (usually presacral retroperitoneal localization) Female gender, middle age

Male or female gender, congenital anomalies, asymptomatic or symptoms due to secondary infection, perforation or compression Other types of solid retroperitoneal neoplasms may be cystic, including paraganglioma, neurogenic tumors, leiomyosarcoma and GISTs

Male or female gender, and abdominal pain due to compression of adjacent structures

Male gender, pediatric age, asymptomatic or symptoms due to complications, including abdominal pain

See Table II any age, palpable mass

\section{Complex mass containing a well-circumscribed fluid component, adipose tissue and calcification}

Thin-walled, multilocular cystic lesion

Unilocular or multilocular thin-walled cyst that contains clear fluid

Thin-walled, unilocular cystic mass with fluid attenuation

Well-defined multicystic mass with various attenuation values, between water and soft tissue, and rare thin calcifications

Rounded well-circumscribed hypoattenuating, or hyperattenuating with protein content, cyst without enhancement Radiological images are particular to each type of tumor and the associated cystic component

Multicystic mass with thick walls or septa and possible curvilinear calcifications

Large thin-walled multiseptate cystic mass with attenuation values between fluid and fat See Table II
Benign

Davidson et al (18)

Benign

Li et al (19)

Benign

Lee et al (20)

Benign

Yang et al (21)

The majority are benign, but malignant change is possible

Benign. Malignant degeneration is extremely rare

Malign

Rha et al (24), Ogose et al (25), MacVicar et al (26) and Chen et al (27)

Benign

Matsuoka et al (28)

Benign

Konen et al (29)

See Table II

See Table II

CT, computed tomography; GISTs, gastrointestinal stromal tumors.

uni- or multi-cystic masses. The malformation appears to arise from sequestration of lymphatic tissue that fails to communicate with lymphatic flow, or from developmental defects during the embryological life stage of the patient, which results from the abnormal budding of the lymphatic endothelium $(7,8)$. However, a pathogenesis associated with abdominal trauma, inflammation due to obstruction of the lymphatic system and radiation therapy have also been suggested as promoting the secondary development of these tumors (9).

Histologically, lymphangiomas consist of 3 distinguishable variants, capillary, cavernous and cystic; the latter is most common. Cystic lymphangiomas are characterized by cystic spaces and dilated endothelium, containing abundant lymphoid tissue and smooth muscle in the cyst wall, with islands of 
Table II. Type and characteristics of pancreatic cystic neoplasms (15).

\begin{tabular}{|c|c|c|c|}
\hline $\begin{array}{l}\text { Type of pancreatic } \\
\text { cystic neoplasm }\end{array}$ & $\begin{array}{l}\text { Epidemiological } \\
\text { and clinical features }\end{array}$ & $\begin{array}{l}\text { Morphological features on } \\
\text { ultrasound and CT scan }\end{array}$ & Malignant potential \\
\hline Serous cystadenoma & Female gender, 7 th & $\begin{array}{l}\text { Microcystic or honeycombed } \\
\text { lesion }\end{array}$ & Rare \\
\hline $\begin{array}{l}\text { Mucinous cystic } \\
\text { neoplasm }\end{array}$ & Female gender, 5th & $\begin{array}{l}\text { Macrocystic malignant lesion } \\
\text { may have a thickened wall or } \\
\text { septations }\end{array}$ & $\begin{array}{l}\text { Degree of epithelial } \\
\text { dysplasia }\end{array}$ \\
\hline $\begin{array}{l}\text { Intraductal papillary } \\
\text { mucinous neoplasm }\end{array}$ & Any gender, 6th-7th & $\begin{array}{l}\text { Mixed features of microcystic } \\
\text { and macrocystic lesions, and a } \\
\text { dilated duct may be present }\end{array}$ & $\begin{array}{l}\text { Degree of epithelial } \\
\text { dysplasia }\end{array}$ \\
\hline $\begin{array}{l}\text { Solid pseudo-papillary } \\
\text { neoplasm }\end{array}$ & Female gender, 4th & $\begin{array}{l}\text { Mixed features of a solid mass, } \\
\text { fluid and hemorrhage }\end{array}$ & Rare \\
\hline $\begin{array}{l}\text { Cystic endocrine } \\
\text { neoplasia }\end{array}$ & Any gender, 5th-6th & Variable features & $\begin{array}{l}\text { Similar to solid } \\
\text { neuroendocrine tumor }\end{array}$ \\
\hline $\begin{array}{l}\text { Ductal adenocarcinoma } \\
\text { with cystic degeneration }\end{array}$ & Male gender, 6th-7th & $\begin{array}{l}\text { Mass with localized adjacent } \\
\text { fluid collection }\end{array}$ & $\begin{array}{l}\text { Similar to solid } \\
\text { adenocarcinoma }\end{array}$ \\
\hline $\begin{array}{l}\text { Cystadenocarcinoma in } \\
\text { acinar cells }\end{array}$ & Male gender, 6th-7th & $\begin{array}{l}\text { Mixed features of microcystic } \\
\text { and macrocystic lesions }\end{array}$ & Similar to solid type \\
\hline
\end{tabular}

ath, 5th, 6th and 7th indicate the decade of life. CT, computed tomography.

Table III. Type and characteristics of non-neoplastic retroperitoneal cystic lesions.

\begin{tabular}{|c|c|c|c|}
\hline Lesion & $\begin{array}{l}\text { Epidemiological and clinical } \\
\text { features }\end{array}$ & $\begin{array}{l}\text { Morphological features on } \\
\text { ultrasound and CT scan }\end{array}$ & First author \\
\hline Hematoma & $\begin{array}{l}\text { History of trauma, ruptured } \\
\text { abdominal aortic aneurysm, } \\
\text { anticoagulation therapy or blood } \\
\text { disease }\end{array}$ & Radiological features of hematoma & Yang et al (14) \\
\hline $\begin{array}{l}\text { Pancreatic } \\
\text { pseudocyst }\end{array}$ & $\begin{array}{l}\text { History of pancreatitis, high } \\
\text { amylase or lipase levels, usually in } \\
\text { the peripancreatic space }\end{array}$ & $\begin{array}{l}\text { Round or oval fluid collection with } \\
\text { a thin or thick wall }\end{array}$ & Balthazar et al (30) \\
\hline $\begin{array}{l}\text { No pancreatic } \\
\text { pseudocyst }\end{array}$ & Asymptomatic & $\begin{array}{l}\text { Unilocular or multilocular } \\
\text { fluid-filled mass with thick walls }\end{array}$ & Ros et al (31) \\
\hline Lymphocele & $\begin{array}{l}\text { History of pelvic or retroperitoneal } \\
\text { lymphadenectomy or renal } \\
\text { transplantation surgery }\end{array}$ & $\begin{array}{l}\text { Fluid-filled cyst with a low or } \\
\text { negative attenuation value due to fat } \\
\text { within the fluid }\end{array}$ & van Sonnenberg et al (32) \\
\hline Urinoma & $\begin{array}{l}\text { History of trauma and presence of } \\
\text { moderate or severe hydronephrosis } \\
\text { in the majority of patients }\end{array}$ & $\begin{array}{l}\text { Fluid collection and water } \\
\text { attenuation that increases } \\
\text { progressively following the } \\
\text { intravenous administration of } \\
\text { contrast material, due to the entry of } \\
\text { contrast-enhanced urine in urinoma }\end{array}$ & Healy et al (33) \\
\hline
\end{tabular}

CT, computed tomography.

lymphocytes in the lumen (10). Immunohistochemically, cystic lymphangioma endothelial cells express factor VIII-related antigen, CD31 and CD34, which are markers for capillary and lymphatic endothelium (6).

Cystic lymphangiomas are usually asymptomatic and found accidentally. In symptomatic cases, the clinical presentations are variable depending upon the location and size of the tumor, but are particularly associated with abdominal pain, abdominal distension and the early onset of the feeling of fullness. On occasion, symptoms may be associated with the onset of complications, including intra-cystic bleeding, infection, rupture of the cyst or compression of 
adjacent organs, and may present in certain cases as an acute abdomen (3).

A definitive diagnosis of cystic lymphangioma is usually made by histological examination subsequent to surgery or exploratory laparoscopy, and a pre-operative diagnosis is rare. The recommended treatment is radical surgical resection. In case of the involvement of the surrounding tissue, the resection should also include the removal of surrounding tissue to ensure complete excision of the tumor, as incomplete resections may be accompanied by an increased risk of recurrence (50\% compared with $7 \%$ for complete resection) $(11,12)$.

Conservative methods, including aspiration, cyst enterostomy and peritoneal marsupialization, are now obsolete due to the high rate of recurrence (3).

Following surgical resection, the correct follow-up program for patients remains unclear. In a study conducted by Makni et al (12), the cases of 20 patients who underwent surgical resection, followed by physical examinations and abdominal ultrasonography for an average period of 5 months (range, 1-60 months), were evaluated. In total, 2/20 patients (10\%) who underwent the surgical removal of the tumor experienced a recurrence of the disease: The first patient relapsed 6 months after a radical intervention and the second patient relapsed 60 months after surgery, due to a partial resection (12). In another previous study, follow-up was considered to be complete at 30 months post-surgery (13).

Despite the absence of large studies in the literature regarding the diagnosis of retroperitoneal cystic masses, distinguishing between neoplastic or non-neoplastic lesions and identifying the type of neoplasm is important, as each tumor demonstrates a varying malignant degeneration risk. A variety of neoplastic retroperitoneal cystic neoplasms (Table I), in particular pancreatic cystic neoplasms (Table II), and non-neoplastic cystic masses (Table III) are considered in the differential diagnosis when a retroperitoneal cystic mass is found $(14,15)$.

In order to diagnose a patient with the aforementioned lesions, certain clinical parameters, including gender, age, presence of symptoms and medical history, particularly a history of pancreatitis, are important to exclude the inflammatory pseudocysts that are associated with chronic pancreatitis (15). The first examination is usually an ultrasound, but assessing the retroperitoneal region is often challenging with this method. By contrast, CT scans allow detailed information on the lesion structure to be obtained through the visualization of the lesion site and size, the presence of calcification or a central scar (highly indicative of serous cystadenomas), the presence of walls, septa and mural nodules, and the involvement of adjacent structures. Particularly in cases of cystic lymphangioma, CT scans show well circumscribed, encapsulated, water-dense, polycystic tumors within septa, which are hardly distinguishable from cystadenomas or from other cystic neoplasms. The attenuation values of CT scans vary between those of fluids and fats. MRI may not provide a better morphological characterization of the mass compared with a CT scan; however, MRI scans reveal the presence of communication between the cyst and pancreatic ducts, which is important in the diagnosis of intraductal papillary mucinous neoplasms $(14,15)$.

The use of endoscopic ultrasound and cyst fluid fine-needle aspiration may be useful to determine the nature and association of cystic lymphangiomas with other structures, and allows better pre-operative characterization of the lesion. Aspirated fluid may be evaluated from a cytological perspective, including the research of tumor cells and atypical lymphocytes, or from a chemical perspective, including measuring levels of amylase and tumor markers. Carcinoembryonic antigen was indicated to be the most useful marker to differentiate malignant potential-mucinous cysts from serous and non-neoplastic lesions in a large prospective study conducted by Khalid et al (16). An increasing level of attention is being focused on the analysis of the DNA quality of fluids and genetic mutation panels, including Kirsten rat sarcoma viral oncogene homolog, p53 and deleted in pancreatic carcinoma 4 mutations, in order to distinguish benign from malignant lesions (16).

Cytological features are useful for the pre-operative diagnosis of lymphangioma, particularly for small and asymptomatic lesions, and include assessment of the triglyceride levels ( 5,000 mg/dl; normal level, <3,000 mg/dl) whereby increased triglyceride levels may indicate lymphangioma, and the presence of lymphocytes and milky fluid (17).

The major epidemiological and morphological characteristics of cystic lesions are summarized in Tables I-III. However, determining a pre-operative diagnosis is often challenging, and in the majority of cases, a diagnosis is only possible subsequent to a histological examination of the surgical specimen.

In conclusion, in the presence of a retroperitoneal cystic mass, clarifying whether the mass is a neoplastic lesion is important in order to understand its nature and malignant potential. The retroperitoneal region is a rare localization of cystic lymphangiomas, however, it should be included in the differential diagnosis of cystic lesions (Tables I-III) (18-33). The recommended treatment for retroperitoneal cystic masses is complete surgical excision, as a partial resection is associated with increased rates of recurrence. The follow-up program is not well established. The two patients in the present study underwent a clinical and radiological surveillance program and, at present, are free of recurrence.

\section{References}

1. Zhou Q, Zheng JW, Mai HM, Luo QF, Fan XD, Su LX, Wang YA and Qin ZP: Treatment guidelines of lymphatic malformations of the head and neck. Oral Oncol 47: 1105-1109, 2011.

2. Ghatak S, Ray S, Sanyal S, Sonar PK, Khamrui S, Basu K, Ray S and Das K: An unusual cause of acute abdomen in adults: Giant cystic lymphangioma of the pancreatic head. A clinical case and literature review. JOP 12: 266-270, 2011.

3. Surlin V,Georgescu E, Dumitrescu C, Râmboiu S,Comănescu MV and Ghiluşi M: Retropancreatic cystic lymphangioma - considerations upon a case. Rom J Morphol Embryol 52 (Suppl): 493-496, 2011.

4. Losanoff JE, Richman BW, El-Sherif A, Rider KD and Jones JW: Mesenteric cystic lymphangioma. J Am Coll Surg 196: 598-603, 2003.

5. Igarashi A, Maruo Y, Ito T, Ohsawa K, Serizawa A, Yabe M, Seki K, Konno H and Nakamura S: Huge cystic lymphangioma of the pancreas: Report of a case. Surg Today 31: 743-746, 2001.

6. Gui L, Bigler SA and Subramony C: Lymphangioma of the pancreas with 'ovarian-like' mesenchymal stroma: A case report with emphasis on histogenesis. Arch Pathol Lab Med 127: 1513-1516, 2003.

7. Gray G, Fried K and Iraci J: Cystic lymphangioma of the pancreas: CT and pathologic findings. Abdom Imaging 23: 78-80, 1998.

8. Schneider G, Seidel R, Altmeyer K, Remberger K, Pistorius G, Kramann B and Uder M: Lymphangioma of the pancreas and the duodenal wall: MR imaging findings. Eur Radiol 11: 2232-2235, 2001. 
9. BhavsarT, Saeed-Vafa D, Harbison S and Inniss S: Retroperitoneal cystic lymphangioma in an adult: A case report and review of the literature. World J Gastrointest Pathophysiol 1: 171-176, 2010.

10. Casadei R, Minni F, Selva S, Marrano N and Marrano D: Cystic lymphangioma of the pancreas: Anatomoclinical, diagnostic and therapeutic considerations regarding three personal observations and review of the literature. Hepatogastroenterology 50: 1681-1686, 2003

11. Cherk M, Nikfarjam M and Christophi C: Retroperitoneal lymphangioma. Asian J Surg 29: 51-54, 2006.

12. Makni A, Chebbi F, Fetirich F, Ksantini R, Bedioui H, Jouini M, Kacem M and Ben Safta Z: Surgical management of intra-abdominal cystic lymphangioma. Report of 20 cases. World J Surg 36: 1037-1043, 2012.

13. Fahimi H, Faridi M, Gholamin S, Molanaee S and Khorsandi M: Cystic lymphangioma of the pancreas: Diagnostic and therapeutic challenges. JOP 11: 617-619, 2010.

14. Yang DM, Jung DH, Kim H, Kang JH, Kim SH, Kim JH and Hwang HY: Retroperitoneal cystic masses: CT, clinical, and pathologic findings and literature review. Radiographics 24: 1353-1365, 2004.

15. Brugge WR, Lauwers GY, Sahani D, Fernandez-del Castillo C and Warshaw AL: Cystic neoplasms of the pancreas. N Engl J Med 351: 1218-1226, 2004.

16. Khalid A, Nodit L, Zahid M, Bauer K, Brody D, Finkelstein SD and McGrath KM: Endoscopic ultrasound fine needle aspirate DNA analysis to differentiate malignant and benign pancreatic masses. Am J Gastroenterol 101: 2493-2500, 2006.

17. Bhatia V, Rastogi A, Saluja SS, Kumar M, Bihari C, Kalayarasan R and Gupta NL: Cystic pancreatic lymphangioma. The first report of a preoperative pathological diagnosis by endoscopic ultrasound-guided cyst aspiration. JOP 12: 473-476, 2011.

18. Davidson AJ, Hartman DS and Goldman SM: Mature teratoma of the retroperitoneum: Radiologic, pathologic, and clinical correlation. Radiology 172: 421-425, 1989.

19. Li YP, Guico R, Parikh S and Chiu S: Cystic mesothelioma of the retroperitoneum. J Clin Ultrasound 20: 65-68, 1992.

20. Lee J, Song SY, Park CS and Kim B: Müllerian cysts of the mesentery and retroperitoneum: A case report and literature review. Pathol Int 48: 902-906, 1998.

21. Yang DM, Yoon MH, Kim HS, Oh YH, Ha SY, Oh JH, Chung HS and Kim HS: Presacral epidermoid cyst: Imaging findings with histopathologic correlation. Abdom Imaging 26: 79-82, 2001.

22. Johnson AR, Ros PR and Hjermstad BM: Tailgut cyst: Diagnosis with CT and sonography. AJR Am J Roentgenol 147: 1309-1311, 1986.
23. Murakami R, Machida M, Kobayashi Y, Ogura J, Ichikawa T, and Kumazaki T: Retroperitoneal bronchogenic cyst: CT and MR imaging. Abdom Imaging 25: 444-447, 2000.

24. Rha SE, Byun JY, Jung SE, Chun HJ, Lee HG and Lee JM: Neurogenic tumors in the abdomen: Tumor types and imaging characteristics. Radiographics 23: 29-43, 2003.

25. Ogose A, Hotta T, Sato S, Takano R and Highchi T: Presacral schwannoma with purely cystic form. Spine (Phila Pa 1976) 26: 1817-1819, 2001.

26. MacVicar AD, Olliff JF, Pringle J, Pinkerton CR and Husband JE: Ewing sarcoma: MR imaging of chemotherapy-induced changes with histologic correlation. Radiology 184: 859-864, 1992.

27. Chen MY, Bechtold RE and Savage PD: Cystic changes in hepatic metastases from gastrointestinal stromal tumors (GISTs) treated with Gleevec (imatinib mesylate). AJR Am J Roentgenol 179: 1059-1062, 2002.

28. Matsuoka Y, Masumoto T, Suzuki K, Terada K, Ushimi T, Yokoyama Y, Abe K, Kamata N, Yasuno M, Hishima T: Pseudomyxoma retroperitonei. Eur Radiol 9: 457-459, 1999.

29. Konen O, Rathaus V, Dlugy E, Freud E, Kessler A, Shapiro M and Horev G: Childhood abdominal cystic lymphangioma. Pediatr Radiol 32: 88-94, 2002.

30. Balthazar EJ, Freeny PC and vanSonnenberg E: Imaging and intervention in acute pancreatitis. Radiology 193: 297-306, 1994.

31. Ros PR, Olmsted WW, Moser RP Jr, Dachman AH, Hjermstad BH and Sobin LH: Mesenteric and omental cysts: Histologic classification with imaging correlation. Radiology 164: 327-332, 1987.

32. vanSonnenberg E, Wittich GR, Casola G, Wing VW, Halasz NA, Lee AS and Withers C: Lymphoceles: Imaging characteristics and percutaneous management. Radiology 161: 593-596, 1986.

33. Healy ME, Teng SS and Moss AA: Uriniferous pseudocyst: Computed tomographic findings. Radiology 153: 757-762, 1984. 